\title{
Technique of Interpretation of Point of Impact Injuries by Using Helmet Deconstruction
}

\author{
Michael Iliescu* MD, Ashley Tessarolo, Kelsey Nelson and Michelle Iliescu \\ Autopsy \& Forensic Services, Inc, USA
}

Submission: December 12, 2017; Published: December 15, 2017

*Corresponding author: Michael Iliescu, Autopsy \& Forensic Services, Inc, USA, Tel: 480-786-4256; Email: miliescu@medexaminer.net

\section{Introduction}

Serious head injury is a common cause of death for motorcyclists involved in fatal accidents. As of 2015 , the Insurance Institute for Highway Safety reports that of fatal motorcycle accidents, $61 \%$ of decedents were wearing helmets. Yet, in the medical examiner's office, the full examination of the helmet is rarely performed due to concerns of damaging the evidence needed for an investigation, since the inner impact liner would have to be removed for thorough examination. Deconstructing the helmet, however, can provide invaluable information in determining the point of impact with another vehicle or the ground when these things are unclear during autopsy based solely on the decedent's injuries. Furthermore, the helmet deconstruction may assist in determining whether multiple head impacts occurred or not. Here, we present a technique to determine the main impact of the head in motorcycle accidents by deconstruction and analysis of the impact liner of the helmet.

\section{Methodology}

Although rarely performed, this helmet deconstruction technique has been invaluable in several different cases. One such case involved a motorcyclist who T-boned a truck and was found underneath the back of the truck after being ejected. A witness testified that the motorcyclist's head was then run over by the truck. An alternative scenario is that the helmeted head was struck by the side of the truck. Unfortunately, the medical examiner could not provide a thorough, accurate description of the original scene, because the bodies and motorcycle had been moved. Therefore, deconstruction helmet analysis was necessary to find the point of impact and the mechanism of trauma. The damage done to the motorcycle and exterior of the helmet was insignificant. However, the inner lining of the helmet was removed for further examination. This was accomplished with extreme caution to avoid further damage and preserve the impact damage. Photographs were taken during the liner removal and after the inspection of the lining for documentation purposes. Once the inner helmet impact liner had been successfully removed, the damage was matched to the damage on the exterior of the helmet. As seen in Figure 1, a fracture of the impact liner corresponded to a scuff present on the outside of the helmet [1].

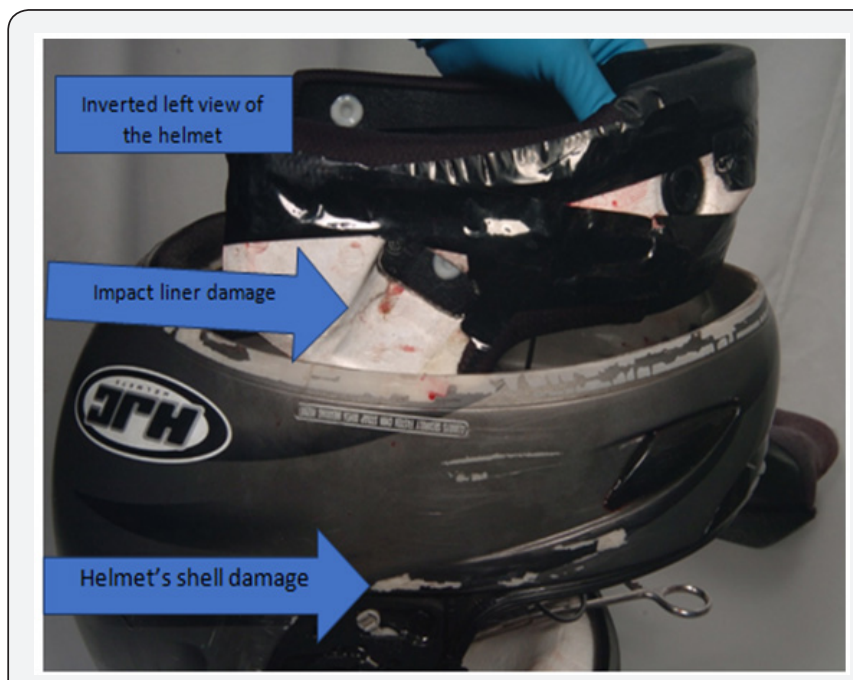

Figure 1: Case 1: Damage of the helmet's impact liner on the left side, corresponding to a skuff mark on the shell of the helmet.

Case 1

Once the damage done to the helmet (the shell and the impact liner) was evaluated, the decedent's injuries to the scalp were attempted to be matched with the damage to the helmet. However, in this case, an external examination of the scalp failed to produce any injuries that matched the impact liner damage and scuff of the helmet. Therefore, an internal examination of the head trauma was performed. In doing so, the medical examiner found a fracture of the left temporal bone located just below the left ear, which was correctly matched to the location of the fracture of the impact liner and the scuff on the helmet's outer shell. In addition, a subgaleal contusion was found just above the line of skull fracture. The combination of impact liner analysis 
and autopsy showed injuries consistent with motorcyclist head impacting the truck resulting in the left temporal bone fracture. Matching of the injuries of the skull and the impact liner of the helmet are documented in the composite Figures $2 \& 3$ below.

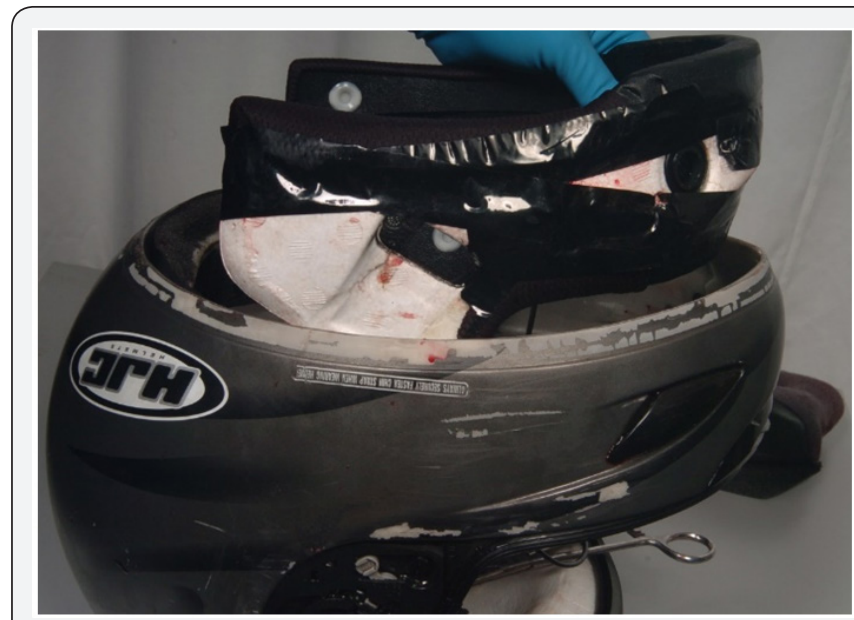

Figure 2: Matching left impact liner damage with the left temporal bone fracture.

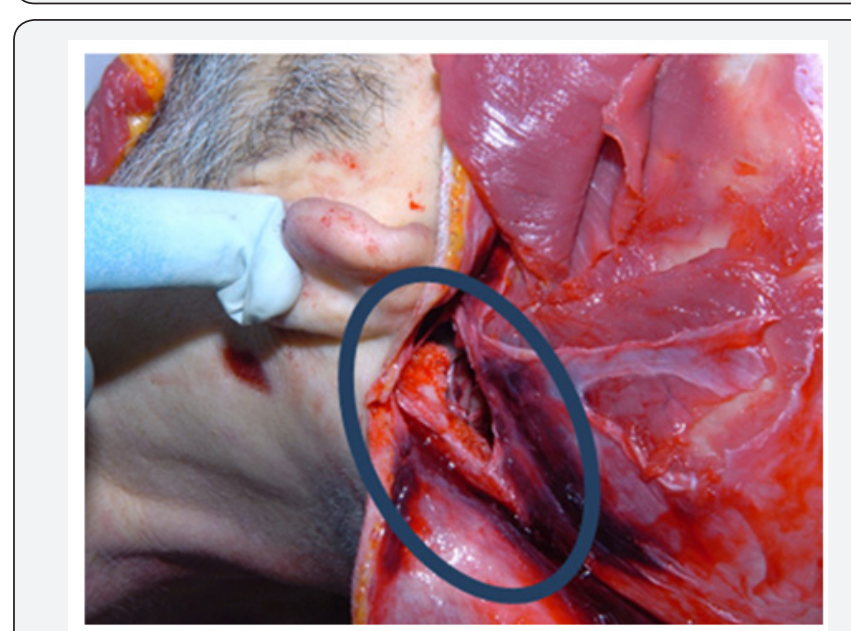

Figure 3: Fracture of the left temporal bone circled above.

We ruled out the theory of the motorcyclist being run over by the truck, which a witness had testified to seeing. In this case, the helmet deconstruction was necessary to determine the single point of head impact on the helmet, and the impacting object (either the vehicle structure or the ground along with the vehicle tire).

\section{Case 2}

Another case in which a "helmet autopsy" was useful in matching the decedent's injuries, case 2, was in the investigation of a motorcyclist and his passenger's (the decedent) collision with a fence pole. The driver lost control of the motorcycle and collided with the fence. From there, there is debate as to what happened and how it happened. Since there were no witnesses to the accident, the deconstruction of the helmet worn by the passenger was necessary in determining the missing information. An initial, external investigation of the helmet showed damage to the leftside of the front of the helmet. This damage matched the skull injuries found during the autopsy of the decedent. In addition, the victim was found lying on the leftside of the face, consistent with her injuries and the damage to the helmet. According to the prosecution, the motorcycle was going at least $85 \mathrm{mph}$ when it collided with the fence. After the collision, the passenger was ejected and landed where she was later found with her helmet several feet away from her.

The defense's version of events is slightly different. According to them, the motorcycle could have been going between 40 $50 \mathrm{mph}$ when it impacted with the fence. After the impact, the passenger was dragged until she reached her final resting place because the trajectory of the motorcycle post-impact could only have ejected her to where she landed at a slower speed. Since the prosecution and defense's theories about the initial speed of the motorcycle and the way the decedent got to her final resting place were so different, the investigation of the damage done to the helmet and the head injuries helped solidify what really happened (Figure 4).

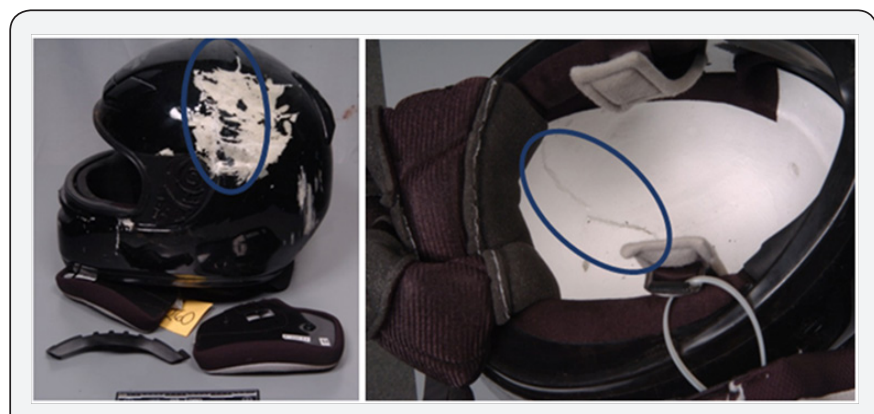

Figure 4: Damage to the left helmet shell and impact liner.
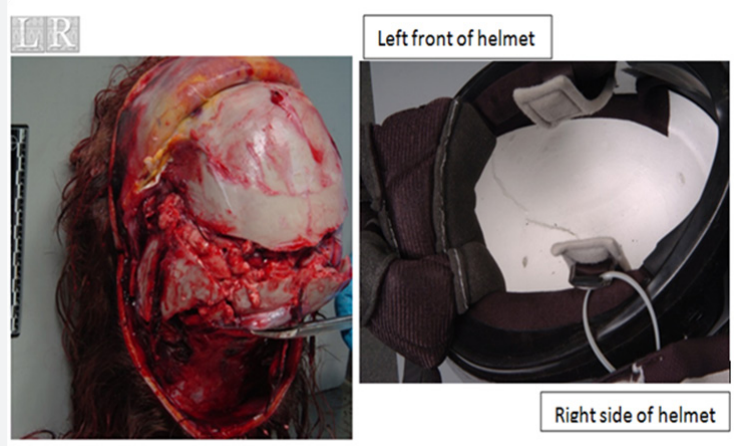

Figure 5: Damage of the skull compared to damage of helmet liner.

Matching of the injuries of the skull and the impact liner of the helmet are documented in the composite Figure 5 below. In this case, the medical examiner would not be able to determine the point of impact to the head based on autopsy alone. Deconstructing the helmet the decedent was wearing during impact clarifies the point of impact based on the helmet damage that corresponds with the decedent's left parietal/temporal area. After the impact, the injury then continued along the back of the skull. 


\section{Results}

These cases show that when there is question of a decedent's sustained head-brain injuries during a fatal motorcycle accident, it is helpful to compare the injuries observed at autopsy with the deformities found on the shell and impact liner of the helmet that was worn during the accident. If a thorough scene investigation by the medical examiner could not be performed due to victims being moved from their initial resting place, as is seen in case 1 , a helmet autopsy can prove useful in clarifying the point of impact, as the helmet lining clearly matched the skull fractures sustained by the motorcyclist.

This work is licensed under Creative Commons Attribution 4.0 License DOI: $10.19080 /$ JFSCI.2017.06.555697

\section{Conclusion}

As shown, helmet autopsies can be a useful tool for the medical examiner in reconstructing what occurred during a fatal motorcycle accident, despite the possibility of introducing artifact damage. Through careful documentation and removal of the impact lining of the helmet, there is minimal damage done and the benefits are many in that they can clarify the origin or cause of the decedents fatal injuries, thus elucidating investigations and legal cases.

\section{References}

1. (1996-2017) Insurance Institute for Highway Safety, Highway Loss Data Institute. Motorcycles and ATVs Fatality.

\begin{tabular}{l} 
Your next submission with Juniper Publishers \\
will reach you the below assets \\
- Quality Editorial service \\
- Swift Peer Review \\
- Reprints availability \\
- E-prints Service \\
- Manuscript Podcast for convenient understanding \\
- Global attainment for your research \\
- Manuscript accessibility in different formats \\
( Pdf, E-pub, Full Text, Audio) \\
- Unceasing customer service \\
Track the below URL for one-step submission \\
https://juniperpublishers.com/online-submission. \\
\hline
\end{tabular}

